$617 \cdot 80$

\title{
consecuencias de la ley editada con objeto de mantener puro el aire en la industria del cemento
}

\author{
folgerungen aus dem gesetz zur reinhaltung der luft für die zement industrie \\ E. RUHLAND
}

( «Zement-Kalk-Gips», 14, núm. 3, marzo 1961, pág. 95.)

Se describen brevemente las prescripciones de la ley para el cambio de las atribuídas a las fábricas (sección 16) y el complemento del código (sección 906) de fecha 22-12-59.

Una Comisión de expertos ha hecho propuestas al Gobierno para establecer un proyecto de ley, sometido a aprobación a causa de las emisiones de gases y polvo. La Comisión de la Asociación de Ingenieros Alemanes para la "Purificación del Aire" se ha encargado de preparar una serie de normas para el Comité de Expertos, relacionadas con la emisión de humos, polvos, gases, etc. Estas directrices serán remitidas por este Comité al Gobierno Federal como instrucciones técnicas para las autoridades encargadas de la inspección industrial.

La industria del Cemento alemana ha examinado, a través de su Comité de Expertos, durante más de veinticinco años, el problema de la emisión de polvo de sus fábricas. Durante más de diez años, esta índustria ha estudiado, a través de las numerosas medidas de su Instituto de Investigaciones, el estado de la técnica de eliminación del polvo en sus fábricas, y ha promovido posteriores mejoras a este respecto.

Las normas establecidas en el año 1958 por la Comísión de la Asociación de Ingenieros Alemanes (VDI) acerca de la emisión móxima de polvo en la industria del cemento, serán revisadas durante el año en curso y puestas al corriente de la técníca. Para la limitación se ha establecido un gráfico que indica el grado de desempolvamiento en función de la producción (las exigencias son más severas para las grandes fábricas). La emisión de polvo en el porvenir puede depender de los valores de admisión fijados para los alrededores, aun cuando estos valores no se han establecido todavia.

Las variaciones en el párrafo 906 del BGD no tendrán consecuencias para las fábricas de cemento, pues ya está probada la inocuidad de las emisiones. No existe, pues, por este lado, un punto de ataque jurídico si se observan las condiciones de la concesión.

Como nueva fuente de perturbación en las proximidades, la industria del cemento debe considerar el ruido $\mathrm{y}$ las sacudidas en los alrededores de las canteras. En las nuevas instalaciones ha sido posible reducir el ruido mediante una construcción adecuada de los edificios. Las normas VDI 2058 se ocupan de este asunto con detalle y ya se emplean como base por las autoridades alemanas. Los problemas especiales de las fábricas de cemento se encuentran en estudio por una Comisión de trabajo de un Comité constituído recientemente (Emissions-au-sschass) de la Asociación de Cementeros Alemanes (VDZ). La medida de vibraciones es difícil de realizar y su interpretación muy discutida, aunque las medidas realizadas hasta la fecha en diferentes fábricas muestran los caminos a seguir para reducir a un mínimo dichas vibraciones. 